\title{
Exploring the Impact of Knowledge Sharing on the Innovative Work Behavior of Employees: A Study in China
}

\author{
Tayyaba Akram ${ }^{1,2}$, Shen Lei ${ }^{1}$, Muhammad Jamal Haider ${ }^{1}$, Syed Talib Hussain ${ }^{1}$ \\ ${ }^{1} \mathrm{PhD}$ Scholar, Donghua University, Shanghai, China \\ ${ }^{2}$ Faculty member, Department of Management Sciences, BUITEMS, Quetta, Pakistan \\ Correspondence: Tayyaba Akram, PhD Scholar, Donghua University, Shanghai, China. \\ Received: August 11, 2017 \\ Accepted: February 16, $2018 \quad$ Online Published: February 19, 2018 \\ doi:10.5539/ibr.v11n3p186 \\ URL: https://doi.org/10.5539/ibr.v11n3p186
}

\begin{abstract}
This study is an attempt to find out the impact of knowledge sharing on the innovative work behavior of employees working in telecommunication sector of China. Particularly, the focus of this study is on the two important dimensions of knowledge sharing namely knowledge donating and knowledge collecting. For this purpose, data of 200 employees from telecommunication sector of China was collected and analyzed through correlation and multiple regression techniques. The results suggest that both knowledge donating and knowledge collecting are positively and significantly affect the innovative work behavior of the employees working in telecommunication industry. However, knowledge collecting was found as a better contributor in facilitating the employee innovative work behavior.
\end{abstract}

Keywords: knowledge sharing, knowledge donating, knowledge collecting, innovative work behavior, China

\section{Introduction}

Why firms need innovation, is evident from the fact that when your competitors are continuously innovating and you are not, it will eventually result your firm to wipe out of the market. This is because creativity and innovative work behavior are the predetermining factors for organizational survival and competitiveness in global economy (Lin, 2007; Raykov, 2014). In today's highly competitive global economy, sustainability of any organization is highly dependent on innovative work and creativity of its employees (Raykov, 2014). Beside this, current era is labeled as the knowledge economy era and knowledge is renowned as an important competitive advantage resource for long term organizational success. Presently, knowledge is considered as a major competitive advantage and hence knowledge management (Lu, Lin \& Leung, 2012). Therefore, in a knowledge intensive era, knowledge sharing is crucial learning strategy for higher innovative performance ( $\mathrm{Lu}$, Lin \& Leung, 2012). The ever changing business environment, tough competition, technological demands by the customers and the importance of knowledge management encouraged contemporary organizations to take such measures that lead to the better utilization of their human resources and this is particularly true for service industry. Previous studies mostly focused on western service sector, while Asian continent is largely missing its representation in literature. Therefore, this study focuses on an emerging telecommunication service industry of China.

China telecommunication industry has a tremendous growth in previous years and its market size has highly increased in past five years (Technavio In sights, 2015). However, this competitiveness leads to further challenges for this industry to stay continuously innovative and competitive in providing high quality services to its millions of customers. For meeting such competitiveness, knowledge sharing is considered a key contributor. Therefore, the aim of this study is to investigate how much the knowledge donating and collecting affects the innovative work behavior of employees working in Chinese telecommunication industry, moreover, which one contributes more in generating innovative work behavior. As per the knowledge of researchers, no previous studies investigated the relationship of knowledge sharing with employee innovative work behavior in the context of knowledge donating and knowledge collecting.

\section{Literature Review}

2.1 Knowledge Sharing

Knowledge management is referred to such process that identifies, shares and utilizes knowledge or the good 
organizational practices that enable organizations to compete (O'Dell \& Grayson, 1998). Further, knowledge sharing is denoted as the "provision of task information and know-how to help others and to collaborate with others to solve problems, develop new ideas or implementing policies or procedures" (Cummings, 2004). Similarly, for successful knowledge management initiatives; knowledge sharing plays a very fundamental role (Wang \& Noe, 2010). Xinyan and Xin (2006) mentioned that in order to create useful knowledge in the workplace, knowledge sharing is used as an important and key method. Therefore, knowledge sharing is considered as a core component of knowledge management (Park, son, Lee \& Yun, 2009). Knowledge sharing is further divided into two sub categories namely knowledge donating and knowledge collecting. Knowledge donating is referred as "the communication between individuals that bases upon an individual's own wishful transfer of intellectual capital", whereas, knowledge collecting is defined as "an attempt to convince other organizational members to share what they know" (Van Den Hooff \& De Ridder, 2004). Eventually, knowledge collecting is consulting and encouraging others to share their intellectual capital (Yesil \& Dereli, 2013; Alhady, Idris, Sawal, Azmi \& Zakria, 2011) and knowledge donating is responding to the same call from others to share one's own intellectual capital. These two forms of knowledge sharing have their own individual standing and effects in the literature which often used interchangeably. Cumming (2003) mentioned five important perspectives that affect the realization of knowledge sharing implementations as the form and location of the knowledge, the relationship between the source of knowledge, the source's knowledge sharing capability, the recipient of knowledge, and the recipient learning tendency, and the broader environment in which the sharing occurs (Yesil \& Dereli, 2013). Hence Knowledge sharing is reflected as "a process where exchange and creation of knowledge among the individuals takes place" (Van Den Hooff \& De Ridder, 2004; Cummings, 2003; Yesil \& Dereli, 2013). Therefore, it plays an important role in employees' innovative work behavior.

\subsection{Employee Innovative Work Behavior}

Innovation studies have been the part of many academic disciplines such as sociology, history management, economics, psychology and industrial design (Jong, 2007). Innovation related studies are found highlighting the importance of innovation related issues crucial for modern economy (Raykov, 2014). Innovative job practices, employee efficiency and contribution in organizational change are key concerns of human resource now-a-days. Due to this importance of organizational innovation, employees' innovative work behavior is the key requirement for success. However, innovative work behavior of the employees is a self-motivated element that is affected by many organizational realities. Innovative work behavior is mostly considered only as idea generation and it is confused with creativity (such as Mumford, 2003; Zhou \& Shalley, 2003). This suggests only a single dimensional measure for innovative work behavior that lacks empirical support and validation (De Jong \& Den Hartog, 2008). Innovative work behavior is therefore, a comprehensive set of behaviors associated to idea generation, idea support within organization and also enabling the implementation of those ideas (Scott \& Bruce, 1994; Janssen, 2000). Janssen (2000) defines innovative work behavior as "intentional generation, promotion and realization of new ideas that are useful for the organizational survival". Further, innovative work behavior is also known as a multiple-stage process in which an individual recognizes a problem for which she or he generates new (novel or adopted) ideas and solutions, works to promote and build support for them, and produces an applicable prototype or model for the use and benefit of the organization or parts within it" (Kanter, 1998; Carmeli, Meitar \& Weiberg, 2006). Hence, innovative work behavior is the "intentional generation, promotion and realization of novel ideas in the workplace" (Janssen, 2001; Scott \& Bruce, 1994; West \& Farr, 1989; Lu, Lin \& Leung, 2012). This definition presents three basic functional elements of innovative work behavior namely creation, promotion and implementation of novel ideas that benefit the organizations (Janssen, 2000, 2004; Scott \& Bruce, 1994; Yuan \& Woodman, 2010). Therefore, EIWB describes employees' findings, their suggestions and implementation of new and beneficiary job related ideas. This study considers innovative work behavior as a multifaceted variable that includes idea generation, idea promotion and idea realization stages altogether. The relationship between knowledge sharing and employee innovative work behavior is discussed further.

\subsection{Relationship Between Knowledge Sharing and Employee Innovative Work Behavior}

Many studies related to knowledge management and organization has strengthen the concept that knowledge sharing ( mostly taken as knowledge transfer and knowledge sharing intensions previously) leads to improvement in organizational performance, such as innovation capability, absorptive capacity and innovativeness (e.g. Liao, Fei \& Chen, 2007; Liu \& Phillips, 2011; Hau, Kim, Lee \& Kim, 2013; Yesil \& Dereli, 2013). Innovation is rendered as "a process through which economic or social value is extracted from knowledge - through the creation, diffusion and transformation of knowledge to produce new or significantly improved products or processes that are put to use by society" (Raykov, 2014). Therefore, innovation is an 
essential competitive strategy and advantage for any firm's survival and keeping itself differentiated. Moreover, it attracts more customers due to the fact that new things are always attractive. Particularly service industry needs continuous innovation to keep its customer base. It is also evident that those employees who are having higher education and knowledge they directly influence the organizational capacity for implementing innovation (Raykov, 2014). Nonetheless, contemporary organizations have tried to sustain their market competitiveness by increasing knowledgeable human capital that is more innovative. Eventually, studies focused on the need of human capital and knowledgeable workforce to meet productivity and innovation related organizational challenges. Number of studies has shown that knowledge management is crucial for enhanced organizational performance (e.g. Perez-Arostegui et al., 2012; Kuo, Kuo \& Ho, 2014) as well as the knowledge sharing and innovativeness (Lin, 2007; Hu et al, 2009; Kuo, Kuo \& Ho, 2014). Beside others factors, knowledge being the most important organizational resource, allows the novel organizational results which also includes the innovation (Kamasak \& Bulutlar, 2010). Moreover, knowledge sharing is found to help people in quickly expanding their individual knowledge range and increase their problem solving ability and work output (Hu et al., 2009).

Knowledge is found to be the main building block for the innovational process. Nonetheless, beside few studies regarding knowledge and innovation, investigation about motivating factors that lead employees to display innovative work behavior are still under study in literature. However, literature supports the link between knowledge sharing and innovation. According to Alhady et al., (2011) the organization that support its employees for contributing knowledge (within groups and organizations) is expected to create new and better ideas and encourage new business opportunities, hence enabling organizational innovation activities. In their study, Kuo et al., (2014) investigated the relationships between workplace friendship, job satisfaction, knowledge sharing and service innovation by collecting data from electronic information engineers at the science parts located in Hsinchu, Thaipei and Tainan. They found a positive and significant effect of workplace friendship and job satisfaction on service innovation and knowledge sharing was found to significantly moderate the effect of job satisfaction and workplace friendship on service innovation. In another study, Choi, Lee and Yoo (2010) found knowledge sharing among team members as an essential element in order to maintain high levels of group and organizational productivity.

Mura et al., (2013) considered knowledge sharing as "sharing best practices" and innovative work behavior only as "idea generation". They found knowledge sharing as a positive contributor towards innovative work behavior. However, knowledge sharing not only let the employees to pass the knowledge to other workers but it also enables others to acquire beneficial knowledge (Kuo et al., 2014). In another study, Lu, Lin and Leung (2012) examined the effects of learning goal orientation on individual innovative work performance with knowledge sharing as the mediator in a survey from 248 employees and their supervisors from diverse industries in China. They found a positive significant effect of learning goal orientation and a significant mediating role of knowledge sharing. Further, Lu, Lin and Leung (2012) investigated the effects of learning goal orientation on individual innovative performance and also observed the mediating mechanisms involved in this process in China. They found learning goal orientation positively related to innovative performance of employees whereas, knowledge sharing was found to mediate this relationship.

Considering knowledge donating and knowledge sharing, Kamasak and Bulutlar (2010), explored the effects of knowledge sharing on innovation. Using multiple regression analysis, they found positive and significant effect of knowledge collecting on all types of innovation; however, knowledge donating was found to have no effect on exploratory innovation. Akhavan, Hosseini, Abbasi and Manteghi (2015) analyzed a comprehensive model of socio-psychological factors, technological and cultural facilitators on the knowledge sharing behaviors and further its impact on the innovative work behavior. However, knowledge sharing was not taken in context of knowledge donating and knowledge collecting, rather considered as "intension to share knowledge". While knowledge sharing is argued as a mechanism by which knowledge can be transmitted between individuals, therefore, through such knowledge transmission, individuals acquire new edge to facilitate new actions. Hence, knowledge sharing contributes value to existing knowledge within the organization and leads to innovativeness. Eventually, literature also highlighted the need for further empirical research on the topic of innovation and skills (Raykov, 2014). This study focuses on these two important parts of knowledge sharing in relation to innovative work behavior, which previously attained less focus by researchers. Instead of only focusing on labor and repetitive activities, knowledge oriented work requires effective knowledge sharing and utilization (Kuo et al., 2014). Innovation is a result of such knowledge exchange that occurs between employees. Knowledge sharing generates key information that ultimately facilitates and predicts organizational innovation (O'Cass et al., 2013; Kuo et al., 2014). 
While sharing their knowledge to their co-workers, individuals not only provide them information but they also combine, elaborate and translate into a clear and relevant form (Hansen, Mors \& Lovas, 2005). In the same way, when the individual collects knowledge from others, he/ she improve his/her capability to innovate (Radaelli et al., 2014). Therefore, it can be proposed that knowledge donating and knowledge collecting positively impacts innovative work behavior of the individuals in organization. Hence, this study hypothesized that knowledge is vital for innovation and therefore, knowledge sharing plays a positive role in generating innovative work behavior in organizational employees. On the base of above literature and arguments, following hypotheses are generated. The hypothetical diagram is also provided in figure 1.

H1: knowledge donating affects EIWB positively and significantly.

H2: Knowledge collecting affects EIWB positively and significantly.

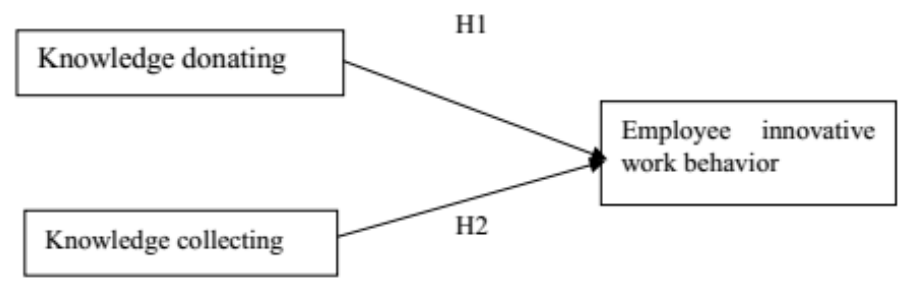

Figure 1. Theoretical Diagram of the Study

\section{Study Material and Method}

\subsection{Sample, Sampling Technique and Sample Size}

The sample was chosen from the telecommunication sector of China on the basis of convenience sampling technique. This technique was suitable as access to employees was not readily available as an easy option for researchers. Analysis of the nature of the data provides the following information. 115 participants were female whereas, 85 participants were male. Range of these participants' ages is from 18 years to 50 years or above, however, majority participants belong to 25 years to 35 years old age group. Employees were contacted by using personal contacts and were requested to fill up a self-administered questionnaire. Initially, 400 questionnaires were distributed, however, 200 were returned with fully filled up and usable condition. The response rate, therefore, was $50 \%$.

\subsection{Data Collection Process}

Using personal contacts, researchers requested the employees of telecommunication sector in Shanghai to fill up the questionnaire with proper instructions mentioned in the questionnaire. They were provided 15 days initially and they were also reminded to fill up the questionnaires on timely basis. However, not all participants were able to fill up and return back these questionnaires, therefore, for maximizing the response rate, few were requested later to fill up the questionnaire in their free time and give back to researchers. In order to generate unbiased responses, all employees were ensured about the anonymity and confidentially of the information they provided.

\subsection{Study Questionnaire}

For measuring the sub dimensions of knowledge sharing, (knowledge donating and knowledge collecting) this study adapted the scale implied by Lin (2007) who used the scale of Van den Hoof and Van Weene (2004). In Lin's (2007) study, knowledge donating comprising of three items, indicated the alpha reliability of 0.78 . Further, knowledge collecting comprising of 4 items had 0.80 alpha reliability. For measuring the innovative work behavior, 9 item scale developed by Janssen (2000) is used. This scale has three dimensions namely idea generation, idea promotion and idea realization and each dimension have three representative items. Overall, Janssen (2000) has mentioned 0.93 alpha reliability for innovative work behavior scale. For ensuring accurate understanding by the participants and maximum response, the questionnaire was further translated into Chinese language. In order to translate the questionnaire, decentering technique was used. Decentering technique of translation is a sequential procedure of translating and retranslating of the questionnaire each time by a different translator (Cateora, Gilly \& Graham, 2013). This technique ensures content validity in translation process, therefore, minimizes the chances of error and enhances the respondent's understanding. A five point Likert scale was used to generate the responses from the participants where $1=$ strongly disagree, $2=$ Disagree, $3=$ neither agree nor disagree, $4=$ Agree and 5= strongly agree. 


\section{Results and Analyses}

\subsection{Descriptive Statistics}

Table 1 presents the descriptive statistics of the study's main variables by providing the minimum, maximum, mean and standard deviation values; it explains the nature of the data and the tendency of the respondents' responses towards this study.

Table 1. Descriptive statistics of the study variables $(n=200)$

\begin{tabular}{lcccc}
\hline Study variables & Minimum & Maximum & Mean & Std. Deviation \\
\hline Knowledge donating & 1 & 5 & 4.12 & .613 \\
Knowledge Collecting & 1 & 5 & 4.15 & .628 \\
Innovative Work Behavior & 1 & 5 & 4.15 & .651 \\
\hline
\end{tabular}

4.2 Cronbach's Alpha Reliability

For ensuring the reliability of the scales used in this study, Cronbach's alpha reliability test was applied. Knowledge donating scale with 3 items presented .849 alpha reliability, whereas, knowledge collecting, with 4 items, presented an alpha reliability of .812. Overall, knowledge sharing scale with 7 items presented .864 alpha reliability. Employee innovative work behavior also confirmed high alpha reliability value of .94 with 9 items. All these scales were proved to be highly reliable for present study. Therefore, further analyses were conducted with confidence.

\subsection{Correlation Analysis}

The results of correlation analysis between knowledge donating, knowledge collecting and innovative work behavior are exhibited in Table 2. All these values are extracted from the correlation table on the base of their significance level at $\mathrm{p}<0.01\left(^{* *}\right)$. A positive and significant relationship was observed between the independent variable, knowledge donating and innovative work behavior $\left(\mathrm{r}=.613^{* *}, \mathrm{p}<0.01\right)$. Further, a significant and positive relationship between knowledge collecting and innovative work behavior is also observable in the table $\left(\mathrm{r}=.678^{* *}, \mathrm{p}<0.01\right)$. Since the two dimensions of knowledge sharing are serving as independent variable and are not highly correlated with each other (two tail inter-item correlation coefficient is $1 \leq$ ), therefore, the problem of multicollinearity was not found in this study. Thus, two measures of knowledge sharing can be used to evaluate the relationship between knowledge donating and knowledge collecting. The correlation found between knowledge donating and knowledge collecting explains that both independent variables are positively related with innovative work behavior of the employees working in telecommunication sector of China.

Table 2. Pearson moment correlation between the independent and dependent variables of the study $(n=200)$

\begin{tabular}{lccc}
\hline Study variables & KD & KC & EIWB \\
\hline Knowledge donating & 1 & $.588^{* *}$ & $.613^{* *}$ \\
\hline Knowledge collecting & - & 1 & $.678^{* * *}$ \\
\hline EIWB & - & - & 1 \\
\hline
\end{tabular}

**. Correlation is significant at the 0.01 level (2-tailed).

\subsection{Hypotheses Testing by Multiple Regression Analysis}

In order to examine the impact of knowledge donating and knowledge collecting on the innovative work behavior of the employees in telecommunication sector, two hypotheses were developed. These hypotheses are assessed and operationalized by using multiple regression technique using IBM SPSS. Table 3 is a representative table for multiple regression results of the study. It is observable from Table 3 that the multiple regression model on the relationship between knowledge donating and knowledge collecting with employee innovative work behavior is significant at $95 \%$ ( $\mathrm{sig}=0.00$ ) confidence interval level. Model presented in Table 3 is a very strong predictor of the relationship between knowledge donating and knowledge collecting with 53\% of the variance explained in employee innovative work behavior by these two variables altogether. Further, coefficients of this model are also provided in Table 3 . To ensure that there is no multicollinearity between explanatory variables of the study, multicollinearity test was also conducted and Tolerance and VIF values are also provided in Table 3. According to Pallant (2013), Tolerance value less than 0.1 and VIF value greater than 10 indicates chances of significant multicollinearity. However, multicollinearity is not the case in this study because tolerance value and VIF values are under the suggestive range. While looking for the $b$ values in Table 3 , both knowledge donating and knowledge collecting were found making a significant $(\mathrm{p} \leq 0.00)$ contribution in explaining variation in innovative work behavior. These standardized coefficients indicate that both knowledge donating $(b=0.328)$ and 
knowledge collecting $(b=0.485)$ have a positive impact on the innovative work behavior of the employees. This suggests that for each single unit increase in knowledge donating and knowledge collecting innovative work behavior is improved by $32.8 \%$ and $48.5 \%$ respectively. These results are further discussed in next section.

Table 3. Summaries of multiple regression analysis for Knowledge donating and knowledge collecting predicting $\operatorname{EIWB}(\mathrm{n}=200)$

\begin{tabular}{|c|c|c|c|c|c|c|c|}
\hline Model & b & B & $\mathbf{T}$ & $\mathbf{p}$ & S.E & \multicolumn{2}{|c|}{ Collinearity Statistics } \\
\hline & & & & & & Tolerance & VIF \\
\hline Constant & & .041 & .149 & .881 & .273 & & \\
\hline Knowledge donating & .328 & .329 & 5.434 & .000 & .061 & .655 & 1.527 \\
\hline Knowledge collecting & .485 & .636 & 8.027 & .000 & .079 & .655 & 1.527 \\
\hline $\mathrm{DR}^{2}=\begin{array}{l}\mathrm{R}=.728 \\
.525 \\
\mathrm{~F}=110.887\end{array}$ & & & & & & & \\
\hline
\end{tabular}

Note. $\mathrm{b}=$ Un-standardized Coefficients, $\mathrm{S} . \mathrm{E}=$ standard error of variables, $\mathrm{b}=$ standardized coefficients, $\mathrm{t}=$ $\mathrm{t}$-statistic, $\mathrm{p}=$ significance level. $\mathrm{R}^{2}=\mathrm{R}$ square

\section{Discussion}

This study aimed at finding out the impact of knowledge sharing in the context of knowledge donating and knowledge collecting on the innovative work behavior of the employees in telecommunication sector of China. Appropriately, after a brief review of the literature, two hypotheses were developed. H1 stated that knowledge donating has a positive and significant impact on innovative work behavior of employees. Results of this study have supported this hypothesis significantly. Knowledge donating is found having a significant impact on innovative work behavior of the employees. Further, $\mathrm{H} 2$ proclaimed that knowledge collecting has a significant and positive impact on the innovative work behavior of employees. Results in Table 3 also support this claim and therefore, $\mathrm{H} 2$ is also supported. The results of present study are in line with previous studies by Liao, Fei and Chen, (2007); Liu and Phillips (2011); Hau et al., (2013); Yesil and Dereli (2013), Lin (2007) and Kuo, et al., (2014) who found knowledge sharing of employees improve the innovative capability and innovation of the firm, however, what effect does knowledge collecting and knowledge donating have on innovative work behavior was not investigated previously. In addition, Lu, Lin and Leung (2012) who suggested in their study that knowledge sharing contributes positively to innovative work behavior of employees are also confirmed in present study. Further Mura et al., (2013) and Akhavan et al., (2015) are among recent researchers who found the positive effect of knowledge sharing on innovative work behavior, however, in these mentioned studies, knowledge sharing was not considered in the context of knowledge donating and knowledge collecting. Results of this study also suggest some interesting fact and details that as compare to knowledge donating, knowledge collecting is a better contributor in innovative work behavior of the employees. That is to say, employees reflect more innovative work behavior when they are able to collect knowledge as compare to donate it. According to Hansen, Mors and Lovas (2005), while sharing the knowledge, individuals not only provide information but they also combine, elaborate and translate into a clear and relevant form. Moreover, when these individuals collect knowledge from co-workers, they improve their capability to innovate (Radaelli et al., 2014). The logic behind readiness of individuals to sharing knowledge in the form of donating and collecting is very obvious. Knowledge sharing (donating and collecting) actually reflects an individual's personal identity and provide them with the realization of self-worth. Moreover, it provides them with satisfaction of self-expression needs (Rahab \& Wahyuni, 2013). However, this study suggests that in Chinese telecommunication industry, workers are more contributing in innovative work behavior when they are able to get more knowledge as compare to those instances when they have to reciprocate this knowledge. Nonetheless, it does not suggest that Chinese employees are less willing to donate their knowledge as the $33 \%$ variation in innovative work behavior caused by knowledge donating ensures that Chinese employees are quite willing to donate their knowledge to co-workers. Their contribution towards innovative work behavior increases when they are able to get relevant knowledge suggests that Chinese workers are more inclined towards innovative work behavior when they get the chances to absorb more knowledge from others. According to Kuo et al., (2014), collegiality among co-workers has an indirect effect on knowledge sharing because it results in lowering greed and increasing self-efficacy. Moreover, organizational support results in better utilization of information and communication technologies and therefore in better knowledge sharing.

\section{Conclusion and Implications}

This study concludes that knowledge sharing in the form of knowledge donating and knowledge collecting is a potential predictor of innovative work behavior of employees in telecommunication industry of China. The 
Theory of Social Exchange supports our findings in a way that individuals are more willing to donate their knowledge if they are also able to collect the knowledge simultaneously in their organizations. Moreover, knowledge collecting and donating generates healthy work environment that leads to new idea generation, idea promotion and idea realization within the organization. Results of this study have some important implications for managers. Initially, organizational leaders should try to provide knowledge sharing environment by encouraging individuals to participate in knowledge donating and knowledge collecting work activities. Motivational factors to share knowledge are different for different individuals. Therefore, identifying the major motivational factors that exist for majority of workers is quite important. Some individuals share the knowledge purely for social acceptance purposes, others, while sharing knowledge, desire knowledge exchange in return. Therefore, the right identification of the motivational factors will help in creating and supporting knowledge sharing environment within organization. Additionally, creating such knowledge sharing environment is quite important for innovation driven industries, both product and service. In order to facilitate idea generation, promotion and implementation, organizations are in need to create knowledge sharing environment and initiate knowledge collecting and knowledge donating driven organizational environment.

\subsection{Study Limitations and Future Research Recommendations}

This study is not free from limitations. First, due to the difficulty in accessing the employees' data bases, data was collected on convenience basis. It is suggested therefore, that if possible, future study can focus on other probability sampling technique to generate better generalization of results. Second, this was a cross sectional study in nature, therefore, further details about the effects of knowledge donating and knowledge collecting can be examined in a longitudinal study in future. In order to get more knowledge, future studies can also focus on other antecedents which affect the innovative work behavior positively or negatively. Analysis of both negative and positive factors can be used to improve the innovative work behavior in knowledge and innovation intensive industries.

\section{About the Authors}

\section{Tayyaba Akram}

Miss Tayyaba Akram is PhD scholar at Glorious Sun School of Business and Management, Donghua University, Shanghai, China and senior Faculty member in the department of management sciences in Balochistan University of Information Technology, Engineering and Management Sciences (BUITEMS), Quetta, Pakistan. Her research focuses on organizational behavior, strategic management, leadership, financial innovation, behavioral finance, social capital, work related stress, emotional intelligence and innovative work behavior.

\section{Professor SHEN Lei}

SHEN Lei is professor in Glorious Sun School of Business and Management, Donghua University, Shanghai, China. Her research interests include organizational behavior, consumer behavior, human resource management and marketing.

\section{Muhammad Jamal Haider}

Mr. Muhammad Jamal Haider has served as visiting lecturer of Economics and Finance in center of international programs (CIP) in Donghua University and he is also PhD scholar in Glorious Sun School of Business and Management, Donghua University, Shanghai, China. His research involves mobile banking, technology adoption, social capital, financial engineering, capital markets, financial innovation, behavioral finance and consumer research.

\section{Syed Talib Hussain}

Syed Talib Hussain is a PhD scholar at Glorious Sun School of Business and Management, Donghua University, Shanghai, China. His research focuses on leadership, change process, motivation, stress, conflict management, consumer research, compensation and reward management in government and private sectors.

\section{References}

Akhavan, P., Hosseini, M., Abbasi, M., \& Manteghi, M. (2015). Knowledge sharing determinants, behaviours and innovative work behaviours: An integrated theoretical view and empirical examination. Aslib journal of information management, 67(5), 562-591. https://doi.org/10.1108/AJIM-02-2015-0018

Alhady, M., Idris, A., Sawal, M., Azmi, N., \& Zakaria, Z. (2011). Knowledge sharing behaviorand individual factors: A relationship study in the i-Class environment. In Proceeding of the international conference on management and artificial intelligence.

Carmeli, A., Meitar, R., \& Weiberg, J. (2006). Self-leadership skills and innovative behaviorat work. 
International journal of manpower, 27(1), 75-90. https://doi.org/10.1108/01437720610652853

Cateora, P. R., Gilly, M. C., \& Graham, J. I. ( 2013). International marketing (Sixteenth edn). New York, America: MacGraw-Hill.

Choi, S. Y., Lee, H., \& Yoo, Y. (2010). The impact of information technology and transactive memory systems on knowledge sharing, application, and team performance: A field study. MIS quarterly, 34, 855-870. https://doi.org/10.2307/25750708

Cummings, J. (2003). Knowledge sharing: A review of the literature.

Cummings, J. (2004). Work Groups, Structural Diversity and Knowledge Sharing in a Global Organisation. Management Science, 50(3), 352-364. https://doi.org/10.1287/mnsc.1030.0134

De Jong, J. P., \& Den Hartog, D. N. (2008). Innovative work behaviour: Measurement and validation. Journal of EIM business and policy research, 1-27.

Hansen, M. T., Mors, M. L., \& Løvås, B. (2005). Knowledge sharing in organisations: Multiple networks, multiple phases. Academy of Management Journal, 48(5), 776-793. https://doi.org/10.5465/AMJ.2005.18803922

Hau, Y. S., Kim, B., Lee, H., \& Kim, Y. G. (2013). The effects of individual motivations and social capital on employees' tacit and explicit knowledge sharing intentions. International journal of information management, 33, 256-266. https://doi.org/10.1016/j.ijinfomgt.2012.10.009

Hu, M. L. M., Horng, J. S., \& Sun, Y. H. C. (2009). Hospitality teams: knowledge sharing and service innovation performance. Journal of tourism management, 30(1), 41-50. https://doi.org/10.1016/j.tourman.2008.04.009

Ibragimova, B., Ryan, S. D., Windsor, J. C., \& Prybutok, V. R. (2012). Understanding the antecedents of knowledge sharing: an organisational justice perspective. Informing Science: the International Journal of an Emerging Trans discipline, 15, 183-206. https://doi.org/10.28945/1694

Janssen, O. (2000). Job demands, perceptions of effort-reward fairness and innovative work behaviour. Journal of Occupational and organisational psychology, 73(3), 287-302. https://doi.org/10.1348/096317900167038

Janssen, O. (2004). How fairness perceptions make innovative behaviormore or less stressful. Journal of Organisational Behaviour, 25(2), 201-215. https://doi.org/10.1002/job.238

Jong, J. P. J. D. (2007). Individual Innovation: The Connection between Leadership and Employees' Innovative Work Behaviour. Doctoral dissertation, University of Amsterdam, Netherland. Retrieved from http://ondernemerschap.panteia.nl/pdf-ez/r200604.pdf

Kamasak, R., \& Bulutlar, F. (2010). The influence of knowledge sharing on innovation. Journal of European business review, 22(3), 306-317. https://doi.org/10.1108/09555341011040994

Kanter, R. M. (1998). From spare change to real change. The social sector as beta site for business innovation. Harvard business review, 77(3), 122-132.

Kuo, Y. K., Kuo, T. H., \& Ho, L. A. (2014).Enabling innovative ability: knowledge sharing as a mediator. Industrial Management \& Data Systems, 114(5), 696-710. https://doi.org/10.1108/IMDS-10-2013-0434

Liao, S. H., Fei, W. C., \& Chen, C. C. (2007). Knowledge sharing, absorptive capacity and innovation capability: An empirical study of Taiwan's knowledge-intensive industries. Journal of information science. https://doi.org/10.1177/0165551506070739

Lin, H. F. (2007). Knowledge sharing and firm innovation capability: An empirical study. International journal of manpower, 28(3), 315-332. https://doi.org/10.1108/01437720710755272

Liu, Y., \& Phillips, J. S. (2011). Examining the antecedents of knowledge sharing in facilitating team innovativeness from a multilevel perspective. International Journal of Information Management, 31, 44-52. https://doi.org/10.1016/j.ijinfomgt.2010.05.002

Lu, L., Leung, K., \& Koch, P. T. (2006). Managerial Knowledge Sharing: The Role of Individual, Interpersonal, and Organisational Factors. Journal of management and organisational review, 2(1), 15-41. https://doi.org/10.1111/j.1740-8784.2006.00029.x

Lu, L., Lin, X., \& Leung, K. (2012). Goal orientation and innovative performance: The mediating roles of knowledge sharing and perceived autonomy. Journal of applied social psychology, 42(1), 180-197. https://doi.org/10.1111/j.1559-1816.2012.01018.x

Mumford, M. D. (2003). Where have we been, where are we going? Taking stock in creativity research. Creativity Research Journal, 15(2-3), 107-120. https://doi.org/10.1080/10400419.2003.9651403

Mura, M., Lettieri, E., Radaelli, G., \& Spiller, N. (2013). Promoting professionals' innovative behavior through knowledge sharing: The moderating role of social capital. Journal of knowledge management, 17(4), 
527-544. https://doi.org/10.1108/JKM-03-2013-0105

O'Cass, A., Song, M. \& Yuan, L. (2013). Anatomy of service innovation: Introduction to the special issue. Journal of business research, 66(8), 1060-1062. https://doi.org/10.1016/j.jbusres.2012.03.002

O’Dell, C., \& Grayson, C. J. (1998). If only we knew what we know: identification and transfer of internal best practices. California Management Review, 40(3), 154-174. https://doi.org/10.2307/41165948

Pallant, J. (2013). SPSS survival manual: A step by step guide to data analysis using IBM SPSS (5 ${ }^{\text {th }}$ edn). Berkshire, England: MacGraw-Hill.

Park, H., Son, S. Y., Lee, S., \& Yun, S. (2009). Organisational justice and knowledge sharing. International Journal of business research, 9(4), 180-185.

Perez-Arostegui, M. N., Benitez-Amado, J., \& Tamayo-Torres, J. (2012). Information technology enabled quality performance: an exploratory study. Journal of industrial management \& data systems, 112(3), 502-518. https://doi.org/10.1108/02635571211210095

Radaelli, G., Lettieri, E., Mura, M., \& Spiller, N. (2014). Knowledge sharing and innovative work behaviorin healthcare: A micro - level investigation of direct and indirect effects. Creativity and Innovation Management, 23(4), 400-414. https://doi.org/10.1111/caim.12084

Rahab, \& Wahyuni, P. (2013). Predicting knowledge sharing intention Based on Theory of Reasoned Action Framework: An empirical study on Higher Education Institution. American International Journal of Contemporary Research, 3(1), 138-147.

Raykov, M. (2014). Employer support for innovative work and employees' job satisfaction and job-related stress. Journal of occupational health, 56, 244-251. https://doi.org/10.1539/joh.12-0192-OA

Scott, S. G., \& Bruce, R. A. (1994). Determinants of innovative behaviour: A path model of individual innovation in the workplace. Academy of management journal, 37(3), 580-607. https://doi.org/10.2307/256701

Van den Hooff, B., \& De Ridder, J. A. (2004). Knowledge sharing in context: the influence of organisational commitment, communication climate and CMC use on knowledge sharing. Journal of knowledge management, 8(6), 117-130. https://doi.org/10.1108/13673270410567675

Wang, S., \& Noe, R. A. (2010). Knowledge sharing: A review and directions for future research. Journal of Human resource review, 20, 115-131. https://doi.org/10.1016/j.hrmr.2009.10.001

Wang, Z., \& Wang, N. (2012). Knowledge sharing, innovation and firm performance. Journal of expert systems with applications, 39, 8899-8908. https://doi.org/10.1016/j.eswa.2012.02.017

West, M. A., \& Farr, J. L. (1989). Innovation at work: Psychological perspectives. Journal of social behaviour.

West, M. A., \& Farr, J. L. (1989). Innovation at work: Psychological perspectives. Journal of social behaviour.

Xinyan, Z., \& Xin, Z. (2006). Moderating effects of organizational justice to knowledge-based psychological ownership and knowledge sharing. In Proceedings of the 8th International Conference on Innovation \& Management.

Yesil, S., \& Dereli, S. F. (2013). An empirical investigation of the organisational justice, knowledge sharing and innovative capability. Procedia-social and behavioural sciences, 75, 199-208. https://doi.org/10.1016/j.sbspro.2013.04.023

Yuan, F., \& Woodman, R. W. (2010). Innovative behaviorin the workplace: The role of performance and image outcome expectations. Academy of Management Journal, 53(2), 323-342. https://doi.org/10.5465/AMJ.2010.49388995

Zhou, J., \& Shalley, C. E. (2003). Research on employee creativity: A critical review and directions for future research. Research in personnel and human resources management, 22, 165-218. https://doi.org/10.1016/S0742-7301(03)22004-1

\section{Copyrights}

Copyright for this article is retained by the author(s), with first publication rights granted to the journal.

This is an open-access article distributed under the terms and conditions of the Creative Commons Attribution license (http://creativecommons.org/licenses/by/4.0/). 